\title{
O discurso histórico como maquinaria de exclusão: um diálogo entre Benjamin e Foucault
}

\section{Osmar Gonçalves dos Reis Filho (UFC)}

Resumo: Através de um percurso pelas filosofias de Walter Benjamin e Michel Foucault, o artigo procura fazer uma análise do discurso histórico oficial, apontando os jogos de rarefação e de exclusão a que está submetido. Pretende-se, em outras palavras, entender os procedimentos formativos da historiografia oficial, o modo como ela se estrutura, o que dá a ver e ilumina, mas também e, principalmente, o que esconde, aquilo que nega e exclui.

Palavras-chave: Historiografia - Discurso - Mecanismos de exclusão

\begin{abstract}
Nunca houve um monumento da cultura que não fosse também um monumento da barbárie. E, assim como a cultura não é isenta de barbárie, não o é, tampouco, o processo de transmissão da cultura.
\end{abstract}

Walter Benjamin.

Precisamos da história, mas não como precisam dela os ociosos que passeiam no jardim da ciência.

Friedrich Nietzsche.

Esse trabalho pretende empreender uma análise do discurso histórico, mais precisamente de seu modelo dominante, a historiografia oficial, tomando como ponto de partida as reflexões de Michel Foucault em A Ordem do Discurso. Neste livro seminal, Foucault nos mostra como os discursos guardam sempre em si uma força, um poder singular e incomensurável, na medida em que eles não só representam as práticas sociais - tal como tende a entender a semiologia e as correntes estruturalistas - mas também as organizam, estruturam, subvertem. Para Foucault, de fato, mais do que representar, o discurso operacionaliza a realidade, estabelecendo com esta uma relação ativa.

Fugindo de uma perspectiva estritamente semiótica, portanto, Foucault nos revela como o discurso transcende o domínio exclusivo da representação, se apresentando como algo operativo, como um dispositivo de poder, um aparato que produz e subverte a realidade, não se limitando apenas a traduzi-la. Nessa perspectiva, o discurso é um perigo que se teme e que, por isso mesmo, procura-se controlar. De acordo com o pensador francês, são muitos os sistemas que controlam e limitam os poderes do discurso. Em sua aula inaugural no Collège de France, Foucault enumera alguns deles, como os tabus, os rituais, o princípio da autoria, os regimes da verdade. Trata-se, em todo caso, de 
mecanismos que procuram rarefazer seus perigos, sublimar sua potência, administrar sua desordem latente.

Pois bem. Nesse pequeno artigo gostaríamos de estabelecer um diálogo com o discurso histórico oficial (tomado aqui como modelo teórico-metodológico) e apontar nele os jogos de rarefação e de exclusão a que está submetido. Dito de outro modo, trata-se de entender os procedimentos formativos da historiografia oficial, o modo como ela se estrutura, para que possamos pensar o que dá a ver e o que esconde, aquilo que ilumina e o que exclui, enfim, os mecanismos que tentam potencializar e rarefazer seus poderes. Para isso, tomaremos de empréstimo alguns conceitos à filosofia de Walter Benjamin, em especial aqueles que encontramos em suas famosas teses Sobre o conceito de história.

Em seu último trabalho, o teólogo e filósofo alemão discuti a necessidade de outra escritura da história, de uma historiografia que estivesse orientada não só para o resgate do passado, mas, simultaneamente, e talvez com maior intensidade, para uma transformação ativa do presente. Tratava-se, nessas teses já tão comentadas, de estabelecer novos princípios para o discurso histórico, princípios que pudessem despertar seus poderes adormecidos, sua desordem e seus perigos, há tanto tempo sublimados pela historiografia oficial. Neste ponto, é pertinente indagar o que seria esse discurso oficial da história, quais são seus fundamentos conceituais, suas características narrativas. Para Benjamin, a história oficial - aquela que nos ensinam nas escolas, que se encontra amparada sobre um suporte e um aparato institucional - fundamenta-se no Historicismo e em suas derivações.

Desenvolvida no século XIX sobre forte influência do positivismo, a historiografia historicista tinha como lema tentar entender o passado "como ele de fato foi". Para que esse objetivo pudesse ser alcançado e os fatos históricos não fossem deturpados pela luz das ideologias correntes, era recomendado ao historiador abandonar seu próprio presente. Sua tarefa consistia, assim, em mergulhar no passado, em fundir-se com o objeto pesquisado, esquecendo todas as outras fases da história.

\section{O método da empatia e o desejo de veneração do passado}

Nessa primeira e ainda insipiente caracterização, já podemos identificar alguns princípios de rarefação do discurso histórico que funcionam como mecanismos de controle, como peças orientadas para conjurar seus poderes. Em primeiro lugar, há a questão da empatia - já vista e analisada por Benjamin na terceira tese. Se o historiador deve fundir-se com o passado, se ele estabelece com esse passado uma relação de identificação e empatia, devemos nos perguntar, afirma o pensador alemão, com quem ele cria essa relação. Segundo Benjamin, trata-se sempre dos vencedores. Pensemos um minuto em nossa história oficial. O que ela representa senão a comemoração das façanhas dos vencedores, a apologia e a rememoração de suas vitórias? Ora, identificarse com os vencedores é excluir da história todos aqueles que foram oprimidos, negados, marginalizados, aqueles que perderam e ainda hoje perdem, pois nem sequer são lembrados. Em termos concretos, falamos aqui dos grupos indígenas, dos negros, mas também dos homossexuais, mulheres e crianças. Todas essas vozes, de forma mais ou menos intensa, acabam escapando à historiografia oficial e, uma vez que não encontram representação na ordem do discurso, dificilmente podem combater ou transformar a ordem das coisas.

Ao lado do princípio da empatia, podemos apontar outro mecanismo de limitação do discurso histórico oficial que, a um olhar menos avisado, apareceria como positividade, como procedimento de correção ou de justiça. Falamos, aqui, do desejo de veneração do 
passado que está na base da historiografia historicista. Com efeito, esquecer os condicionamentos do presente, desprezar a si mesmo e mergulhar no passado, tinha como resultado mais freqüente não o regaste ou a conservação de um período histórico, mas sua adoração - o culto a um tempo perdido! Na maioria das vezes, o que o historiador historicista nos legava era a descrição de um passado harmonioso e feliz. Tudo o que pudesse haver de terror, de desgraça ou sofrimento era, então, excluído e apagado.

O próprio método da empatia respondia por esse processo, pois, ao invés de colocar o historiador numa posição crítica e distanciada, fazia com que ele se fundisse ao passado, estabelecendo um tipo de relação que culminava quase sempre no culto ou na adoração do fato histórico. À primeira vista, essa "docilização" do passado poderia ser encarada como um ato de justiça, como uma correção da dureza e das imperfeições da história, mas é aí justamente, nesse apagamento da dor, nessa subtração do ódio que opera o mais imperceptível dos mecanismos de controle. Pois, se há algo de combativo e violento no discurso histórico, Benjamin assegura que ele certamente está ligado aos sentimentos de ódio e de vingança com os quais a classe oprimida de hoje se lembra de seus antepassados excluídos e escravizados. $\mathrm{O}$ verniz que o historiador tradicional coloca sobre a história não serve senão para dobrar sua força, para subtraí-la de toda possibilidade de subversão, de reversão ou de violência.

Em Vantagens e desvantagens da história para a vida, Nietzsche critica esse mesmo desejo de veneração do historiador historicista e o compara a um mau músico que toca apenas os sons suaves e delicados. Segundo Nietzsche, "isso é como adaptar a Sinfonia Heróica para duas flautas, para o uso determinado de sonhadores fumadores de ópio" ". O historiador, neste caso, não é mais do que um artífice da narcose e o discurso histórico, uma espécie de compressa quente, um bálsamo anestésico que, a exemplo da música trágica, alivia momentaneamente, mas só ao preço de um mal mais grave e permanente, o conformismo.

De fato, enquanto princípio formativo, tanto o método da empatia quanto o desejo de adoração do passado acabam levando o sujeito a uma atitude passiva e paralizante. Em ambos os casos, as injustiças da história não são apenas maquiadas ou reinterpretadas, elas, efetivamente, são excluídas do discurso histórico. Contudo, existem ainda, na historiografia historicista, outros procedimentos de rarefação do discurso que respondem mais diretamente à vontade de conformismo. A intenção de fixar uma imagem "eterna" do passado, de conhecer o fato histórico por ele mesmo, abandonando, assim, todo e qualquer presente, é o primeiro deles.

\section{O desprezo pelo presente}

Uma tal intenção implica necessariamente no desconhecimento e no desprezo pelo presente. De acordo com esse princípio, a tarefa do historiador não tem nenhuma relação com o momento atual. Pelo contrário, ele deve virar as costas ao presente, preocupandose apenas em apresentar uma imagem fiel e única do passado. Ora, a primeira conseqüência desta atitude é a transformação da história numa "mania antiquária", numa espécie de discurso anticrítico, dedicado simplesmente a arquivar e a tesaurizar o passado. A história se vê transformada, assim, numa grande "loja de antiguidades", numa narrativa eloqüente que apresenta um após o outro, sem distinções de proporção ou de valor, os diversos períodos históricos. Parafraseando as críticas de Nietzsche a esse mesmo princípio historicista, Ernani Chaves afirma que: 
A conseqüência mais brutal disso tudo é transformar o "talento" para o pensamento em "curiosidade insaciável", numa avidez em querer conhecer tudo o que é antigo, até o ponto de "devorar com prazer, até mesmo o pó das minúcias bibliográficas"2.

De fato, o que temos, aqui, mais uma vez, é um certo esmorecimento do pensar, a assunção de uma postura passiva frente à história, no duplo sentido de narrativa e de acontecimento. Pois, com seu desprezo ao presente, o Historicismo não apenas transforma a história numa grande "loja de antiguidades", sem fim e sem propósito, mas também desvincula o ser humano do que acontece aqui e agora, impedindo-o de tomar o momento atual como foco de interesse. Ora, se existe algum poder na historiografia, se há de fato algo de combativo no discurso histórico, ele deveria estar voltado para o presente, para o que se dá aqui e agora - para o único tempo que, num certo sentido, realmente existe. direcioná-lo ao passado, é domesticar seus perigos, privá-lo de suas forças.

Em História e Narração em Walter Benjamin, Jean-Marie Gagnebin traça um percurso filosófico intricado e exaustivo para conhecer a historiografia salvadora que Benjamin evoca em suas famosas teses. Ao final de seu trajeto, ela chega à conclusão de que, independente de quais sejam as características particulares dessa narrativa, para que ela possa alcançar toda sua potência transformadora (tal como imaginada pelo filósofo alemão), ela deve certamente estar direcionada para o presente. O historiador materialista é aquele que lembra "por amor ao passado e a seus sofrimentos esquecidos, decerto, mas igualmente, de maneira ainda mais perigosa, lembra-se por amor ao presente e à sua necessária transformação"3.

Por isso, Benjamin contrapõe, nas teses, o conceito de um tempo "homogêneo e vazio", tal como praticado pelo Historicismo, ao conceito de um tempo saturado de "agoras". O Jetztzeit benjaminiano descreve um presente que tem singularidade e qualidade próprias, que apresenta, em contraponto a outros períodos da história, um valor diferenciado. Trata-se de um momento significativo que é, ao mesmo tempo, surgimento do passado no presente e evento do instante; um presente, enfim, que, acima de tudo, não é visto como mera transição. Pelo contrário, ele tem a peculiar característica de parar no tempo e se imobilizar.

O historiador materialista, aquele que saberia dizer essa narrativa salvadora, só aproxima-se de um objeto histórico quando ele se apresenta como Jetztzeit. Nem tudo, portanto, é merecedor de sua atenção. Na verdade, a grande maioria dos fatos é destituída de interesse para esse historiador. Segundo Benjamin:

Ele deixa a outros a tarefa de se esgotar no bordel do historicismo, com a meretriz "era uma vez". Ele fica senhor de suas forças, suficientemente viril para fazer saltar pelos ares o continuum da história. ${ }^{4}$

Um período histórico só é digno de sua atenção se ele estiver dialeticamente ligado ao presente, se, em outras palavras, ele estiver presente ainda hoje e oferecer, por esse contato insuspeito, uma oportunidade de se lutar por um passado oprimido. Para o historiador materialista, o conhecimento do passado não tem uma finalidade em si mesmo. Devemos conhecer e nos lembrar, decerto, mas não de tudo e de igual maneira. 
Quem impõe as questões e incita as lembranças é o presente. Se não quisermos transformar a história num grande bordel, é nele e por ele que devemos conhecer.

\section{O passado "como ele de fato foi"}

Em A Ordem do Discurso, Foucault procura identificar os jogos e os sistemas de rarefação que se impõem sobre a prática dos discursos. Entre os inúmeros procedimentos que o pensador francês encontra - alguns de natureza externa como o tabu do objeto, o ritual da circunstância, outros de natureza interna ao discurso como o princípio das disciplinas e o conceito do autor - tem certo destaque a vontade de verdade. Ao longo dos tempos, essa vontade sempre foi vista como positividade, como a essência e a instância supremas, como o valor dos valores, enfim.

Para Foucault, no entanto, a vontade de verdade é apenas mais um dos mecanismos de controle do discurso. Certamente, um dos mais importantes, na medida em que é dele de que menos se fala hoje. Enquanto os outros sistemas se tornam cada vez mais frágeis, enquanto parece não haver mais tabus ou rituais que permaneçam fechados às malhas do discurso, a vontade de verdade se fortalece, atravessando e reorganizando ao redor de si todos os outros sistemas. Mas, afinal de contas, o que há de controlador ou limitante no conceito de verdade? Não seria ela a própria essência dos fenômenos, um absoluto que valeria em todos os tempos e em todos os lugares? Algo que é pura ciência, que está além de qualquer interesse ou perspectiva? Justamente, e aqui residem quase todos os males, os equívocos, os enganos.

"Não podemos enxergar além de nossa esquina", , afirmou o primeiro filósofo a pôr seriamente em questão nossa vontade de verdade. Segundo Nietzsche, não há como nos situarmos fora de nossas experiências, de nossas percepções; a existência, como um todo, está condicionada pela perspectiva e sua injustiça. Conseqüentemente, não existem transparências ou neutralidades na ordem do discurso, toda narrativa é enviesada, singular e se encontra atravessada pelos mais diversos desejos e interesses.

Nesse sentido, o que quer um discurso que se apresenta como verdadeiro, como um abstrato universal, senão iludir, ludibriar? Em forma de indagação, o próprio Foucault responde a essa pergunta:

É que se o discurso verdadeiro não é mais, com efeito, desde os gregos, aquele que responde ao desejo ou aquele que exerce o poder, na vontade de verdade, na vontade de dizer esse discurso verdadeiro, o que está em jogo, senão o desejo e o poder? ${ }^{6}$

Sob o rótulo cristalino e transparente da verdade, esconde-se, portanto, uma intensa vontade de poder. O discurso que se apresenta como verdadeiro não procura apenas se esquivar de toda crítica, de toda suspeita, ele tem como objetivo central negar outros pontos de vista, outras versões e perspectivas que são, certamente, tão pertinentes quanto aquela que se pretende verdadeira. Nesse sentido, a vontade de verdade é um dos principais mecanismos de controle e de exclusão do discurso histórico oficial. Ela o envolve numa aura de conformismo e de passividade que é difícil desfazer - pelo menos, enquanto ainda perdura em nossa cultura uma concepção metafísica e essencialista de verdade. Pois o que há para se desconstruir ou para ser transformado, se estamos diante não de perspectivas, mas de fatos da exata maneira como eles realmente aconteceram. Ora, o próprio Benjamin denunciou essa postura positivista do Historicismo. Na obra das 
Passagens, ele afirma que "a história, que mostrava a coisa "como ela de fato foi", era o narcótico mais forte do século"7.

Com efeito, da maneira como está estruturado hoje, o discurso histórico oficial não é nada além de um narcótico, uma grande maquinaria de exclusões destinada a sedar as energias revolucionárias da história. É preciso despertar os poderes do discurso, afrouxar suas cadeias, reformular seus princípios. Nesta tarefa, pode ser de grande ajuda o acaso, as falhas, as lacunas do sentido. Pois, como conclui Gagnebin, ao final de sua busca pela historiografia salvadora benjaminiana, é somente "em nossas hesitações, em nossas dúvidas, em nossos desvios, que pode ainda se insinuar o apelo messiânico, ali, enfim, onde renunciamos a tudo preencher para deixar que algo de outro possa dizer-se" ${ }^{\text {. }}$.

Abstract: Through a route into the philosophies of Walter Benjamin and Michel Foucault, the article attempts to make an analysis of the official historical discourse, pointing out the games of rarefaction and exclusion that it is submitted. It is intended, in other words, to understand the procedures of the official historiography formation; the way as it is structured, which gives the view, but mainly, it hides, which excludes and denies.

Keywords: Historiography - Discourse - Mechanisms of exclusion

\section{Referências bibliográficas}

CHAVES, Ernani. No limiar do moderno: estudos sobre Friedrich Nietzsche e Walter Benjamin. Belém do Para: Paka-Tatu Ltda, 2003.

GAGNEBIN, Jean-Marie. História e Narração em Walter Benjamin. São Paulo: Perspectiva, 1999.

FOUCAULT, Michel. A Ordem do discurso. São Paulo: Edições Loyola, 2005.

NIETZSCHE, Friedrich. A Gaia Ciência. Trad. Paulo César de Souza. São Paulo: Companhia das Letras, 2004.

NIETZSCHE, Friedrich. Da utilidade e desvantagem da história para a vida. In: Os Pensadores. 3 ed. São Paulo: Abril Cultural, 1983.

OTTE, Georg. Linha, choque e mônada [manuscrito]: tempo e espaço na obra tardia de Walter Benjamin. UFMG, 1994.

\section{Notas}

${ }^{1}$ NIETZSCHE, Friedrich. Da utilidade e desvantagem da história para a vida. In: Os Pensadores. 3 ed. São Paulo: Abril Cultural, 1983, p. 64. 
${ }^{2}$ CHAVES, Ernani. No limiar do moderno: estudos sobre Friedrich Nietzsche e Walter Benjamin. Belém do Para: Paka-Tatu Ltda, 2003, p.55.

${ }^{3}$ GAGNEBIN, Jean-Marie. História e Narração em Walter Benjamin. São Paulo: Perspectiva, 1999, p. 104-105.

${ }^{4}$ BENJAMIN, Walter. Sobre o conceito de história. In: Obras Escolhidas (vol.1). Magia e técnica, arte e política. Trad. Sérgio Paulo Rouanet. São Paulo: Brasiliense, 1987, p. 231.

${ }^{5}$ NIETZSCHE, Friedrich. A Gaia Ciência. Trad. Paulo César de Souza. São Paulo: Companhia das Letras, 2004, p. 278.

${ }^{6}$ FOUCAULT, Michel. A Ordem do discurso. São Paulo: Edições Loyola, 2005, p. 20.

${ }^{7}$ Citado por OTTE, Georg. Linha, choque e mônada [manuscrito]: tempo e espaço na obra tardia de Walter Benjamin. UFMG, 1994.

${ }^{8}$ GAGNEBIN, Jean-Marie. História e Narração em Walter Benjamin. São Paulo:

Perspectiva, 1999, p. 98. 